\title{
Longitudinal Mechanisms Linking Perceived Racial Discrimination to Aggressive Delinquency among North American Indigenous Youth
}

\author{
Dane Hautala, \\ University of Minnesota Medical School, Duluth Campus, Department of Family Medicine and \\ Biobehavioral Health, 1035 University Drive, 230 SMed, Duluth, MN 55812 \\ Kelley Sittner \\ Oklahoma State University, Department of Sociology, 471 Murray Hall, Stillwater, OK 74078
}

\begin{abstract}
Objectives: Drawing from an integrated general strain theory framework, the purpose of the study is to examine the longitudinal mediating and moderating mechanisms linking perceived racial discrimination with aggressive delinquency among North American Indigenous (i.e., American Indian and Canadian First Nations) youth.

Methods: Data come from an eight-year longitudinal study of Indigenous youth residing on reservations/reserves in the upper-Midwest and Canada $(N=659)$. Scales were created for discrimination, depressive symptoms, school bonds, and delinquent peer associations at years 2 and 3, and a count measure of aggression was created at years 2,3, and 5. Cross-lagged path analysis models were estimated to examine possible mediating effects of depressive symptoms, school bonds, and delinquent peer associations. Separate regression models were examined to test for possible moderating effects of the aforementioned variables.
\end{abstract}

Results: The results of a longitudinal path analysis model showed that discrimination indirectly increased aggression through decreased school bonds and increased delinquent peer associations. Depressive symptoms was the only significant moderator, and contrary to expectations, the effect of discrimination on aggression declined in magnitude as depressive symptoms increased.

Conclusions: Discrimination is a key criminogenic stressor among Indigenous youth and is linked with multiple adverse outcomes through the adolescent years.

\section{Keywords}

Discrimination; American Indian; First Nations; Race; General Strain Theory

Indigenous people experience disparate rates of violence and victimization compared to other racial and ethnic groups (McNulty and Bellair 2003), and are overrepresented at every stage of the criminal justice system, with approximately one-third of Indigenous males expected to experience incarceration at least once in their lifetime (Duran and Duran 1995). 
Despite this, little attention has been paid to understanding the social context of North American Indigenous (i.e., American Indian and Canadian First Nations) delinquency and the general and unique criminogenic mechanisms that produce it. The exclusion of Indigenous people in mainstream criminological research is reflective of broader cultural and structural inequalities perpetuated by the enduring legacy of colonialism, which keeps many of the social problems salient in Indigenous communities out of the purview of the discipline of criminology and society at large (Martin 2014). Undoing this colonial legacy requires scholars to focus on issues relevant to Indigenous communities, adapting mainstream theories to account for unique contexts, and prioritizing research methods that emphasize community involvement and cultural specificity.

Variations in offending by race/ethnicity are a function of differences in experiences within the social environment that are associated with offending (Agnew 2016). Pridemore (2004) argued there are characteristics that make Indigenous "individuals and communities especially likely to experience specific types of risk, and that these cultures and communities also possess unique features that will aid in providing protective factors against these risks" (pg. 54). Furthermore, the geographic, cultural, historical, and social contexts of many Indigenous reservation/reserve communities shape a unique developmental milieu for Indigenous youth that is not shared by any other group (Whitbeck et al. 2014), and is continually shaped by historical cultural losses and traumas (Evans-Campbell 2008). For Indigenous people, many disparities in physical and behavioral health stem from these social determinants, rather than individual or collective pathology (Evans-Campbell 2008).

Disparate rates in violence and victimization among Indigenous people can be viewed as an ongoing response to oppression, which is perpetuated by multilayered discrimination (Poupart 2002). Racial discrimination has been shown to be a culturally-salient risk factor for a wide range of criminogenic outcomes for Indigenous youth (Hautala et al. 2015; Mmari, Blum, and Teufel-Shone 2010; Whitbeck et al. 2014); however, few studies examine and contextualize the mechanisms through which discrimination leads to delinquency among this population. Racial discrimination and its pernicious effects have been used to explain the link between race and crime (Burt, Simons, and Gibbons 2012; Kaufman et al. 2008; Unnever and Gabbidon 2011), and mounting evidence shows that they may be key drivers of racial and ethnic disparities in offending (Bogart et al. 2013) for African Americans and Latinos. Examining mechanisms that link perceived racial discrimination to delinquency has important theoretical and pragmatic implications. Theoretically, understanding the conditions (i.e., mediating and moderating) under which various strains such as discrimination are associated with delinquency may elucidate ways in which macro-level racial stratification and socio-historical experiences (e.g., historical trauma) shape racialized interpersonal processes (Burt et al. 2012) that impact Indigenous youth. Pragmatically, this examination may offer insights to ameliorate the negative consequences of discrimination on Indigenous adolescent development and the communities in which they occur.

Although many theories appear to be applicable to Indigenous youth and various theoretical components (e.g., risk and protective factors) operate similarly (Pridemore 2004), the social backdrop that gives rise to these processes are likely unique, rendering them similar in function, but different in context (Hautala, Sittner, and Whitbeck 2016; Whitbeck, Sittner 
Hartshorn, and Walls 2014). Agnew's (Agnew 1992; Agnew 2001; Agnew 2006) General Strain Theory (GST) and complementary frameworks (e.g., Unnever and Gabbidon 2011) provide a theoretical lens through which general and contextual factors salient to Indigenous offending can be examined and is adaptable to explain variations in offending by race/ ethnicity (e.g., Kaufman et al. 2008; Leeper Piquero and Sealock 2010). The purpose of this study is to examine the longitudinal mediating and moderating mechanisms through which perceived racial discrimination from adult authority figures impacts delinquent behavior among a sample $(n=659)$ of reservation/reserve residing Indigenous youth in the upperMidwest and Canada.

\section{Context of Discrimination}

Socio-historical processes resulting from European colonization, including forced assimilation through boarding schools, relocation programs, and continued assaults on tribal sovereignty represent key aspects of historical trauma that shape broader Indigenous experiences (Whitbeck et al. 2014). Crime in Indigenous communities can be understood as a response to this ongoing historical oppression (Poupart 2002), which is perpetuated through multilayered discrimination (Burnette and Figley 2017). Unnever and Gabbidon (2011) constructed an analogous explanatory model for African American offending. They argued that offending can only be understood through the unique world-view shared by many African Americans, which has been dynamically shaped through a legacy of slavery, Jim Crow era laws, and continued policies aimed at maintaining white supremacy. Different Latino and Asian subgroups, on the other hand, have varying levels of social capital and experience with U.S. and Canadian culture, and likely vary on exposure to perceived discrimination. Moreover, degree of acculturation, ethnic identity, and other cultural factors may be important for influencing exposure to perceived discrimination and its consequences among these groups (Alegria et al. 2004). Despite these distinct socio-historical worldviews, perceived discrimination appears to be a general risk factor for racial and ethnic minorities (Priest et al. 2013). The historic and contemporary backdrop of discrimination and the ways in which it manifests, however, are best understood when situated in the social contexts in which they occur.

Although a thorough synthesis is beyond the scope of this paper, discrimination among North American Indigenous populations has deep historical roots stemming from European colonization (Evans-Campbell 2008) and is perpetuated by Indigenous people's continued colonized status (Walters and Simoni 2002). Robertson (2015) argued that multilayered racism and stereotypes against Indigenous people are deeply woven into North American society and have been normalized and institutionally legitimized, making them invisible within social norms and major social institutions. For example, Indigenous people continue to face contemporary forms of overt racism (e.g., national holidays romanticizing colonizers, stereotyped sports mascots, and appropriating Indigenous culture for play and dress) and enduring colonial stereotypes (e.g, "drunken Indian"; Fryberg et al. 2008). Consequently, the blame for many social problems in Indigenous communities is shifted away from their structural socio-historical roots and toward individual and collective pathology (Robertson 2015). As a result, historic and contemporary racism against Indigenous people is intricately embedded into the social fabric that shapes racial discourses and produces an ongoing 
context in which communities, families, and individuals operate (Belcourt-Ditloff and Stewart 2000; Evans-Campbell 2008). Intergenerational historical trauma magnifies the impacts of discrimination and increases its cultural significance (Belcourt-Ditloff and Stewart 2000). These racial discourses manifest at the microlevel through racist interactions, which are characterized as blatant, subtle, and covert beliefs, emotions, behaviors and practices of a dominant racial and ethnic majority group that have a detrimental impact on a subordinate racial and ethnic minority group (Priest et al. 2013). Although racism and discrimination occur at multiple levels, the focus of the current study is on interpersonal experiences of perceived racial discrimination rather than internalized or systematic forms of discrimination (hereafter, we use the term discrimination to refer to perceived racial discrimination).

Most prior studies on discrimination and crime make the implicit assumption that it is the amount of discrimination experienced or perceived that matters, rather than specific subdomains that comprise most measures of discrimination (Bastos et al. 2010). For example, much of the prior research on discrimination and crime primarily focus on African American experiences and use data from the Family and Community Health Study (FACHS; Brody et al. 2006; Brody, Kogan, and Chen 2012; Burt, Lei, and Simons 2017; Burt and Simons 2015; Burt et al. 2012; Evans, Simons, and Simons 2016; Gibbons et al. 2004; Simons and Burt 2011; Simons et al. 2003) or the Project on Human Development in Chicago Neighborhoods Study (PHDCN; Riina et al. 2013; Unnever, Cullen, and Barnes 2016a; Unnever, Cullen, and Barnes 2016b). The FACHS study used an adapted version of the Schedule of Racist Events (Landrine and Klonoff 1996) which focuses on how often participants perceived a variety of discriminatory experiences from global sources (e.g., how often has someone). The PHDCN focuses on whether or not (yes or no) participants perceived discrimination in a variety of locations (e.g., work, neighborhood, health care center).

Discrimination, however, is a multidimensional construct differentiated by contextual domains (e.g., place of occurrence, characteristics of the perpetrator, type of discrimination; Benner et al. 2018; Brondolo et al. 2005; Riina et al. 2013; Rucker, Neblett, and Anyiwo 2014). Emerging research suggests that the different domains of discrimination map onto specific developmental outcomes, rather than act as general risk factors (Benner and Graham 2013; Benner et al. 2018; Brondolo et al. 2005). For example, Benner and Graham (2013) found that school-related discrimination was associated with declines in academic performance, whereas peer-related discrimination was associated with increased negative affect. No crossover effects were observed. Similar arguments have been made in the GST literature. For example, DeCoster and Kort-Butler (2006) found support for the argument that stressors exert their strongest effects on criminological outcomes within the same domain as the stressor (e.g., family stressors have strongest effect on family-related delinquency), and weaker effects across domains. Taken together, the domain in which stressors such as discrimination occur matters for particular outcomes, rather than being general risk factors. To effectively examine the mechanisms through which discrimination is likely to lead to crime, a crucial next step is to start interrogating whether and how various dimensions of discrimination are differentially associated with criminogenic processes. In an attempt to conceptually and methodologically refine this growing body of research, we 
emphasize forms of discrimination perpetrated by an adult authority figure (e.g., school staff, business owners, police, general adults), which we believe has particular salience during adolescence, and trace how perceptions of discrimination within this domain are likely to lead to specific criminogenic processes within a GST context.

\section{General Strain Theory}

Agnew's (Agnew 1992; 2001; 2006) GST offers a theoretical lens through which the intervening and conditional mechanisms linking discrimination to delinquency can be examined. Recent iterations of GST (Agnew 2006) integrate a number of mechanisms from other criminological theories to explain the strain-delinquency association (see Jang and Rhodes 2012 for empirical support). Agnew (2006) argued that GST has strong potential to elucidate the causes of crime that are central to other theoretical frameworks such as emotional temperament, social bonds, and delinquent peer associations. An integrated framework derived from GST is thus useful to examine relevant mechanisms linking perceived racial discrimination to delinquency among Indigenous youth, and similar to other stress process frameworks (e.g., Pearlin 1989), is flexible enough to allow us to account for the unique cultural and historical context of Indigenous populations (Pridemore 2004).

In his initial presentation of GST, Agnew (1992) described crime or delinquency as a possible adaptation to three types of strains: the presentation of negative stimuli, the removal of positively valued stimuli, or the inability to achieve a desired goal or outcome.

Discrimination is an example of a noxious stimulus. Agnew (2001) further specified the characteristics of criminogenic strains that are likely to lead to delinquency: (1) strains high in magnitude, (2) strains viewed as unjust, (3) strains associated with low social control, and (4) strains that create pressure for delinquency. The theory has been tested and supported in Indigenous samples for understanding substance use (Eitle, Eitle, and Johnson-Jennings 2013), suicidal behavior (Ivanich and Teasdale 2018; Walls, Chapple, and Johnson 2007), and delinquency (Baek, Roberts, and Higgins 2018; Eitle and Eitle 2016). Yet, these applications of GST for understanding Indigenous delinquency have important limitations. Most of the objective strains tested in these studies align with Agnew's (2001) criteria for those most likely to lead to delinquency (e.g., negative life events, negative relationships with family members, victimization); missing is consideration of culturally specific strains like discrimination. Moreover, a majority of these studies relies on data collected across Indigenous cultural groups and geographic contexts, which results in pan-Indigenous generalizations that fail to account for wide-heterogeneity in cultural and historical circumstances of Indigenous populations.

Culturally relevant strains such as discrimination have unique historical and contemporary relevance, are highly prevalent, and are qualitatively more criminogenic among Indigenous youth than "general" strains. Discrimination overwhelmingly meets all four of Agnew's (2001) aforementioned criteria. First, discrimination based on race/ethnicity may be considered an identity salient stressor (Thoits 1991), and thus, one that is highly central and damaging to a person's racial/ethnic identity. Second, discrimination also violates a widely valued social norm of equal treatment, which may promote feelings of injustice. Third, chronic experiences of discrimination may undermine social bonds with major social 
institutions and stakes in conformity, thereby reducing social control (Unnever and Gabbidon 2011). Fourth, repeated experiences of discrimination teach lessons about the ways in which society works and may be internalized as social schemas that justify offending (Burt and Simons 2015; Burt et al. 2017).

Work by Sittner Hartshorn and colleagues (2012) represents the only study of which we are aware to include discrimination as a strain that impacts delinquent behavior among Indigenous youth, using a within-culture design (the same sample used in the current study). Although not explicitly focused on GST, Sittner Hartshorn et al. (2012) tested the associations among discrimination, anger, and delinquency, and found discrimination to precede delinquent behavior and to affect delinquency indirectly through anger. We advance the use of GST to explain Indigenous delinquency by examining the culturally salient strain of discrimination using longitudinal data from one Indigenous cultural group. We embed the framing and results within these unique social contexts, establish proper time ordering among relevant constructs, and expand the mediating and moderating mechanisms that link discrimination to delinquency.

\section{Mediating Mechanisms}

Although discrimination may directly influence delinquency when its frequency and intensity are high (e.g., Unnever and Gabbidon 2011), the most potent explanations linking discrimination to aggression are indirect through secondary criminogenic factors (e.g., Agnew 2006). Discrimination influences the inner-worlds of Indigenous adolescents and their early experiences with social institutions (Whitbeck et al. 2014), the social consequences of which link it with adverse developmental outcomes such as delinquency. The first part of the proposed model suggests that the effect of discrimination on delinquency is mediated by personal and social mechanisms such as negative affect, social bonds, and delinquent peer associations.

Negative emotions are central to GST (Agnew 1992; Agnew 2001; Agnew 2006). Exposure to strains, such as discrimination, induces negative affect, which creates pressure for corrective action, delinquency being one possible outcome. Likewise, Unnever and Gabbidon (2011) argue that racial discrimination in particular influences offending through the oscillating feelings of depression, anger, and defiance, which likely co-occur in complex ways. Non-parental adults are an important source of support for youth and promote resiliency and psychological well-being beyond parental and peer relationships (Sterrett et al. 2011). Perceptions of discrimination emanating from adult figures, however, likely reduces the odds of forming and maintaining these quality relationships, and may result in feelings of psychological distress. Alternatively, discrimination and the messages of inferiority it conveys, especially when it originates with adult authority figures, may become internalized leading to increased depressive symptoms. Discrimination is a consistent and robust predictor of negative mental health outcomes among Indigenous (Whitbeck et al. 2001; Whitbeck et al. 2014) and general U.S. adolescents (Priest et al. 2013) and adults (Pascoe and Richman 2009). 
Although anger is central in GST, and is the most commonly examined negative emotion, Agnew (2006) also argued that strain-induced depression likely creates pressure for corrective action and reduces the ability to cope. Moreover, anger is often thought to lead to externalized forms of delinquency such as aggression, whereas depressive symptoms are thought to lead to internalized forms of delinquency such as substance use (Agnew 2006). This argument, however, is overly simplistic and not consistently supported by evidence. Prospective research suggests changes in depressive symptoms predict changes in aggression either more strongly than the reverse (Kofler et al. 2011) or the relationship only flows from depression to aggression (Beyers and Loeber 2003). This may be because irritability, withdrawal, and isolation are key symptoms of depression among adolescents, which leads to acting out (Kofler et al. 2011). Further, the association between discrimination and delinquent behavior has been found to operate through depressive symptoms for African American youth (Brody et al. 2006; Gibbons et al. 2004; Simons et al. 2003), and depressive symptoms have been shown to account for the association between various strains and suicide ideation (Ivanich and Teasdale 2018; Walls et al. 2007) and heavy alcohol use (Eitle et al. 2013) among Indigenous youth. From this, discrimination is expected to be associated with delinquency through increases in depressive symptoms (Hypothesis 1).

Agnew (2006) also argued that strains may temporarily reduce social controls which makes delinquent coping more likely to occur. Recent evidence indicates that discrimination undermines embeddedness into supportive social relationships (Burt et al. 2017) and major social institutions such as schools (Unnever et al. 2016a), which explains the heightened levels of delinquent behavior among minority youth relative to whites. Among African American adolescents, discrimination was associated with delinquency through decreased school engagement (Brody et al. 2012; Unnever et al. 2016a) and reduced commitment to conventional norms (Burt et al. 2012). Chronic and repeated experiences of discrimination from adult authority figures (e.g., school staff) may intentionally or unintentionally serve as reminders of cultural and racial inferiority, thereby reducing one's emotional attachment to these conventional figures and diminishing the inhibitory effect that school attachment has on delinquent behavior.

This general argument would appear to apply to Indigenous youth. During adolescence, youth spend a large portion of their time within school settings. Although school experiences are a robust source of resilience among Indigenous youth (LaFromboise et al. 2006), discrimination has been shown to decrease school bonds in early adolescence (Whitbeck, et al. 2014). Moreover, Indigenous youth who experience high levels of discrimination show steeper declines in school adjustment from grade school to high school than those who experience less discrimination (Crawford, Cheadle, and Whitbeck 2010). This effect is even more pronounced for youth who attend off reservation/reserve schools, which is often a necessity given the rural nature of many of these communities, where mixed-race interactions are more common (Crawford et al. 2010). School bonds decrease the odds of delinquent behavior and conduct disorder for Indigenous youth, even when accounting for other criminogenic factors such as parenting, delinquent peer associations, and prior delinquency (Sittner and Hautala 2016; Whitbeck et al. 2014), and may account for differences in violent delinquency between Indigenous and white youth (McNulty and 
Bellair 2003). From this, discrimination is expected to be associated with delinquency through its undermining effect on school bonds (Hypothesis 2).

In addition to negative affect and social bonds, Agnew (2006) argued that strain may temporarily foster the social learning of crime, and tests of GST have found that strains are associated with delinquent behavior through delinquent peer associations (Jang and Rhodes 2012). Cumulative experiences of strain may decrease one's stake in conformity and make delinquent peer relationships more attractive (Agnew 1992). Discrimination from adult authority figures may be a signal of social rejection based on racial/ethnic differences, which leads to feelings of devaluation and demoralization (Whitbeck et al. 2014), and decreases the extent to which individuals develop trusting, supportive, and prosocial relationships (Burt et al. 2017). Persistent experiences and perceptions of discrimination perpetrated by adult figures combined with social and geographic isolation present in many reservation/reserve communities (Pridemore 2004) are likely to cause youth to drift into relationships that eschew respect for conventional norms, and bond more closely with other disaffected youth (Brody et al. 2012). The rural and cultural context of many reservations/reserves may influence the size and composition of peer networks, such that youth are embedded in dense and enduring social networks making delinquent peer associations a salient source of risk for antisocial behavior among this group (Whitbeck et al. 2014). Consequently, delinquent peer associations may act as a strong link between racial discrimination and delinquent behavior.

Several studies have examined the relationship between discrimination and delinquent peer associations, which show a modest positive relationship (e.g., Brody et al. 2012; Gibbons et al. 2004; Simons and Burt 2011). Research further indicates that delinquent peer associations account for part (Cheadle and Whitbeck 2011; Gibbons et al. 2004; Simons and Burt 2011; Unnever, Cullen, and Barnes 2016b) or all (Brody et al. 2012) of the association between discrimination and delinquent behavior. Whitbeck and colleagues (2014) found in their study of Indigenous youth that the effect of delinquent peer associations on delinquency is so robust that it often overshadows the statistical effects of other social processes such as parenting practices. Research among Indigenous youth also suggests that early delinquent peer associations predict chronic trajectories of aggressive delinquency across the course of adolescence (Sittner and Hautala 2016). From this, discrimination is expected to be associated with delinquency through increases in delinquent peer associations (Hypothesis 3).

\section{Moderating Mechanisms}

In addition to the indirect effect of discrimination on delinquency through various personal and social mechanisms, GST specifies multiple conditional (moderating) relationships that influence the odds that individuals will react to strain in a delinquent manner. The second part of the proposed model suggests that the effect of discrimination, regardless of source, on delinquency may be conditioned on the mechanisms discussed above, rather than operating through them. First, Agnew (2006) argued that trait-based negative emotions may moderate the association between strain and delinquency. Consistent with prior research (Dodge and Pettit 2003; Piquero et al. 2011), emotions encapsulated by depression shape cognitive schemas conducive toward aggressive behavior through selective attention to 
certain social cues (e.g., less aware of the full range of consequences of crime), interpreting other's intentions as hostile (e.g., more likely to experience emotional reactions to strain), and decreased ability to respond to strain in a non-criminal manner. Adolescents who exhibit high levels of depressive symptoms are more likely to be irritable, impatient, and explosive (Berkowitz 1989) as well as being withdrawn from others (Schaefer, Kornienko, and Fox 2011). Likewise, depressive symptoms undermine youths' aspirations and hopes for the future which promotes feelings of hopelessness (Nyborg and Curry 2003) and "nothing to lose" attitudes (Harris, Duncan, and Boisjoly 2002). Although the moderating effect of depression has yet to be examined in the discrimination literature, prior research suggests that depressive symptoms increases the odds that individuals react to strains such as victimization with delinquency (e.g., Manasse and Ganem 2009). As such, the positive association between discrimination and delinquency is expected to be amplified for those high in depressive symptoms, compared to those low in depressive symptoms (Hypothesis 4).

Second, GST suggests that adolescents low in social control are less able to cope with strain in legitimate ways, making delinquency a more likely outcome. Although discriminatory experiences may undermine minority youths' bonds to schools, some youth retain their attachment and commitment to school, which may be reflective of positive racial socialization experiences (Unnever and Gabbidon 2011). As previously noted, school bonds are a strong source of resilience among Indigenous youth (LaFromboise et al. 2006). Consequently, the costs of engaging in delinquent behavior are greater for those most attached to school because delinquency jeopardizes one's bond with this institution. Conversely, the costs of engaging in delinquency are lower for those low in social control, which increases the odds that strains will produce delinquent coping responses. This assertion has been supported among African American samples in which school bonding and efficacy were found to buffer the effect of discrimination on delinquency (Brody et al. 2006; Unnever et al. 2009). Therefore, we hypothesize that school bonds will buffer the effect of discrimination on delinquency (Hypothesis 5).

Third, Agnew (2006) argued that peers are likely to promote the reappraisal of stressors as high in magnitude and unjust, reduce the perceived costs of crime, and provide little support for legal coping. Peers provide opportunities for delinquency, promote the learning of definitions favorable toward crime, and reinforce delinquent behaviors (Warr 2002). In addition, developmental models suggest that youth who experience discrimination are likely to attribute it as such if others (e.g., peers) affirm their attribution (Brown and Bigler 2005). Brody and colleagues (2006) found among African American youth that prosocial peer relationships buffered the association between discrimination and delinquency. The reverse is also expected to hold true, but remains untested in the extant discrimination literature. For example, although there is mixed support for a moderating effect of delinquent peer associations in the GST literature (e.g., Moon et al. 2009), several studies have found that delinquent peer associations amplify the strain-delinquency relationship (Mazerolle and Maahs 2000; Mazerolle et al. 2000). As such, the positive association between discrimination and delinquency is expected to be amplified for those high in delinquent peer associations (Hypothesis 6). 
To summarize, discrimination is a chronic stressor with deep historic and contemporary roots among Indigenous youth, and is implicated in worse physical, mental, and behavioral outcomes. Despite this, we found only one other study of Indigenous youth that has examined indirect mechanisms linking discrimination to delinquency (Sittner Hartshorn et al. 2012). Criminological research on this issue has almost exclusively focused on African American samples (e.g., Burt et al. 2017) and has relied on cross-sectional or partially longitudinal data in which the full temporal ordering cannot be established among all constructs of interest (e.g., Hoskin 2013; Unnever et al. 2016a). The current study advances this emerging literature by examining an under-studied racial/ethnic sociopolitical group, Indigenous youth, using a wider array of mediating and moderating mechanisms with fulllongitudinal data. We also extend this literature by focusing on experiences of perceived discrimination within one specific domain (i.e., adult authority figures), rather than assume all domains of discrimination influence different criminogenic processes equally. We first consider mediating processes linking early discrimination to later aggression through producing more proximal risk factors such as depressive symptoms and delinquent peer associations, and/or by depleting school bonds, a protective factor. We then consider moderating effects with depressive symptoms and delinquent peer associations expected to amplify the discrimination-delinquency association, and school bonds expected to buffer this association.

\section{METHOD}

\section{Sample}

To test these hypotheses, data for the present study come from an eight-wave longitudinal study that was designed in partnership with three U.S. reservation and four Canadian First Nations reserve communities (for more details on the study design, see REMOVED FOR BLIND REVIEW). Although participants were recruited from different reservation/reserve communities, all participants are members of the same cultural group and share a common cultural tradition and language. The study is representative of one of largest Indigenous cultural groups in the U.S. and Canada, and includes among the largest and smallest federally recognized reservation/reserve communities within this group. Because of heterogeneity in cultural, geographic, and historic experiences among North American Indigenous cultures, the target population for this study was restricted to one culturallydefined population to avoid making pan-Indigenous generalizations, which is a common and problematic practice in criminology (Pridemore 2004). The tension of all studies lies between cultural specificity and generalizability (Beals et al. 2003). In this case, the community based participatory research approach and goals of translating findings for local program and policy change initiatives underscores the tremendous value of within-group/ culture studies that can maximize validity and community involvement in the research process.

Prior to the start of the study, tribal resolutions were obtained from each location and community advisory boards were established. As part of confidentiality agreements, the names of the cultural groups and reservations/reserves are not identified, nor are any attempts made to make comparisons across locations. In each community, advisory boards 
were responsible for handling personnel issues and advising the research team on all aspects of the project. All participating staff on the reservations/reserves (i.e., interviewers, site coordinators) were approved by their respective advisory boards and were either enrolled tribal members or spouses of enrollees. Interviewers for this project were trained annually concerning methodological guidelines of personal interviewing and all were certified for work with human subjects.

At the beginning of the study, each community provided a list of families of tribally-enrolled children aged 10-12 years who lived on or near (within 50 miles) the reservation/reserve. The research team attempted to contact all families with a target child within the specified age range to achieve a population sample. Families for this study were recruited through personal interviewer visits during which they were presented a traditional gift, an overview of the project, and an invitation to participate. For those families who agreed to participate, both the study adolescent and at least one adult caretaker (and in some cases, two adults) were given $\$ 20$ upon completion of the interviews. The response rate for the initial baseline interviews was $79.1 \%$. The first wave of data were collected in 2002, and participants were interviewed annually for eight years. Recruitment and incentive procedures were approved both by community advisory boards and [removed for blind review] Institutional Review Board.

The data used in the current study come from wave 2 (W2), wave 3 (W3), and wave 5 (W5; Wave 4 did not assess variables of interest). At W2, the sample was evenly split by gender. The average age of the participants was 12.09 years (S.D. $=.86$ ), and approximately one in ten $(11.0 \%)$ adolescents lived in a remote location (i.e., the community is not fully accessible by road at all times of the year and is a prohibitive distance from a larger community). A total of 659 adolescents ( $88 \%$ of the baseline sample) completed at least one of the waves included in this study (W2 - 636; W3 - 626; W5 - 605). We conducted an attrition analysis to assess whether those who dropped out at each wave and those who dropped out at any wave were different from the original Wave 1 sample. We examined all constructs included in this study, along with other items that may be relevant (e.g., meeting diagnostic criteria for various psychiatric disorders, residing on/off reservation land, per capita family income). We found no differences between those with missing data and those with complete data on all items. Because the missing at random assumption appears tenable, full-information maximum likelihood estimation was used to account for item missing data and missing data due to wave non-completion ( $84.9 \%$ had complete data at all waves-see Table 2 for item missingness).

\section{Measures}

Aggressive delinquency (waves 2, 3, and 5).-Aggressive delinquency consists of nine (0) no or (1) yes items, which were adapted from the conduct disorder module of the Diagnostic Interview Schedule for Children IV (DISC-IV; Shaffer et al. 2000). Respondents were asked whether or not in the past 12 months they have engaged in various aggressive behaviors (i.e., attacking someone to steal, threatening someone to steal from them, starting a fire without permission, physical cruelty to an animal, bullying others, being in a physical fight, and hurting someone with a weapon). An index of aggressive behavior was created by 
summing the nine items together (W2 Kuder Richardson $20[\mathrm{KR}]=.68$; W3 KR $=.69$; W5 $\mathrm{KR}=.69)$.

Perceived racial discrimination (waves 2 and 3).-Discrimination from adult authority figures was measured with five items adapted from the Schedule of Racist Events (Landrine and Klonoff 1996). Respondents were asked how often in the past 12 months they have perceived that adult figures (e.g., store owner, sales clerk, police, adults, teachers, and school staff) discriminated against them because they are a member of [cultural group] (Table 1 presents the exact wording of each item). Response options ranged from (0) never to (2) many times. A continuous scale was created by summing the items together (W2 $a=$. $71 ; \mathrm{W} 3 \mathrm{a}=.74)$.

Depressive symptoms (waves 2 and 3).-Depressive symptoms were assessed using a 19-item version (see Armenta et al. 2014) of the Centers for Epidemiological StudiesDepression Scale (CESD; Radloff 1977). Respondents were asked how often in the past week they had experienced various symptoms associated with depression (e.g., I felt depressed, I enjoyed life). Response options ranged from (0) rarely or none of the time to (3) most or all of the time. All positively worded questions were reversed coded. The 19 items were summed to form a scale of depressive symptoms (W2 $a=.87$; W3 $a=.87$ ).

School bonds (waves 2 and 3).--School bonds were assessed using seven (0) disagree or (1) agree items about school attitudes/behaviors (see Crawford et al. 2010). Respondents were asked if they like school a lot, do well in school, try hard at school, get good grades, get along with teachers, try hard at difficult classes, and teachers think they are a good student. The agree responses were summed to create an index of school bonds (W2 KR = . 77 ; W3 KR = .75).

Delinquent peers (waves 2 and 3).-A measure of peer delinquency was created using nine commonly used items about the respondent's friends. Participants were asked how many of their three best friends smoke cigarettes, drink alcohol, don't get along with their parents, have gotten into trouble at school, have gotten in trouble with the police, are sexually active, have parents who drink or use drugs, have played the pass-out/black-out game, and use meth. Response options ranged from (0) no friends to (3) three friends. The items were averaged to create a scale of peer delinquency (W2 $a=.81$; W3 $a=82$ ).

Controls (wave 2).-Three demographic variables that have been shown to be associated with aggressive behavior and/or perceived racial discrimination among Indigenous youth were controlled for in the analyses. Males tend to engage in more aggressive behavior than females. In addition, aggression patterns tend to increase through mid- to late-adolescence and decrease thereafter (Sittner and Hautala 2016). In addition to gender and age, adolescents living in remote communities (those not accessible by road at all times of the year and a prohibitive distance from larger communities) tend to experience less discrimination than youth living in non-remote communities (Whitbeck et al. 2014). As such, for each endogenous component of the model, gender $(0=$ male; $1=$ female $)$, age (continuous), and remote location $(0=$ rural, non-remote community; $1=$ remote community) were controlled for. 


\section{Analytic Strategy}

The mediation hypotheses were tested via lagged panel path analysis models (see Cole and Maxwell 2003) by assessing the significance of the indirect effect of perceived discrimination on aggression through the hypothesized mediators (see Figure 1). Autoregressive paths from W2 aggression to W3 aggression, W3 aggression to W5 aggression, and W2 mediators to W3 mediators were added to control for prior levels of each mediator/outcome and to assess residual change over time (Cole and Maxwell 2003). In addition, paths from $\mathrm{W} 2$ discrimination to the $\mathrm{W} 3$ mediators and aggression, $\mathrm{W} 2$ mediators to W3 aggression, and W3 discrimination and mediators to W5 aggression were added to set up the basic mediation panel model (Cole and Maxwell 2003; Maxwell, Cole, and Mitchell 2011). Variables within each wave were allowed to covary with one another.

Longitudinal indirect effects were calculated by multiplying the path coefficient from discrimination at W2 to the mediator at W3 (path a) with the path coefficient from the mediator at W3 to aggression at W5 (path b). The significance of the indirect effect was assessed using 95\% bias-corrected bootstrap confidence intervals (95\% CI) based on 5,000 bootstrap resamples (Shrout and Bolger 2002). Simulation studies suggest that traditional approaches (e.g., Sobel tests) result in low statistical power and make unrealistic assumptions about the distribution of the indirect effect (MacKinnon, Lockwood, and Williams 2004). Bootstrapping is a non-parametric approach that does not make distributional assumptions and has been shown to reduce type II error, while adequately controlling type I error inflation (MacKinnon et al. 2004). As such, we report the biascorrected bootstrap confidence intervals to assess the significance of the indirect effects.

Moderation was tested in separate models for W3 aggression using W2 predictors, and W5 aggression using $\mathrm{W} 3$ predictors. Interaction terms were created by centering continuous variables at their maximum likelihood mean estimate and multiplying discrimination by depressive symptoms, school bonds, and delinquent peer associations and testing each interaction separately (see Enders, Baraldi, and Cham 2014). Significant interactions were probed at $-/+1$ S.D. around the mean for discrimination and the moderator. For additional context, simple slopes were calculated to assess the significance of discrimination on aggression at low ( -1 S.D. below the mean) and high levels (+1 S.D. above the mean) of the moderator.

Full-information maximum likelihood estimation with chi-square and standard errors robust to non-normality (Yuan and Bentler 2000) were used to estimate the models and account for missing data in Mplus Version 6 (Muthen and Muthen 1998-2010). Alternative estimation procedures such as negative binomial regression with numerical integration, and bootstrapping with bias-corrected confidence intervals generated similar findings to the robust maximum likelihood estimator. Model fit was assessed using root mean square error of approximation (RMSEA), comparative fit index (CFI), and standardized root mean residual (SRMR) estimates. A CFI value of .95 or higher, an RMSEA value below .06, and an SRMR value below .08, with converging evidence across fit indices, indicates adequate model fit (Hu and Bentler 1999). 


\section{RESULTS}

Table 1 displays the prevalence of discrimination from adult authority figures at the second and third waves of the study. At W2 and W3, the most common sources of discrimination were school staff, followed by teachers, adults working at a place of business, and adults in general. Discrimination from law enforcement was the least endorsed form in both waves, with approximately $5 \%$ of adolescents perceiving any discrimination from this source. A total of $39.6 \%$ and $42.1 \%$ adolescents reported perceiving any of the five forms of discrimination "a few times" or "many times" in the past 12 months at W2 and W3, respectively. A continuous summed measure of all five items was used in the subsequent analyses.

Table 2 presents all of the maximum likelihood descriptive statistics and correlations for all variables included in the analyses. The bivariate analyses indicated that discrimination was positively associated with aggression at all three waves $(p<.05)$. Moreover, the bivariate results indicated that discrimination was associated with all of the hypothesized mediating/ moderating variables in the expected direction, and all mediating/moderating variables were significantly associated with aggression in the expected direction $(p<.05)$.

\section{Mediation Model}

The proposed mediation model provided an adequate fit to the data. The modification indices, however, suggested that adding a path from W2 school bonds to W3 delinquent peer associations would appreciably improve model fit. The proposed model with this new path added provided a good fit to the data $\left(\chi^{2}=45.42(17), p<.01 ; C F I=.98 ; R M S E A=.05\right.$; $S R M R=.03$ ). No additional paths significantly improved the basic mediation model (see Figure 1).

The results of the final mediation model are presented in Table 3 and summarized in Figure 1 . There were several differences between the bivariate and lagged multivariate analyses. Discrimination at $\mathrm{W} 2$ had a positive association with $\mathrm{W} 3$ delinquent peer associations $(\beta=$. $08, p<.05)$ and a marginal positive association with $\mathrm{W} 3$ depressive symptoms $(\beta=.07, p=$. $08)$. Discrimination at $\mathrm{W} 2$ was negatively associated with $\mathrm{W} 3$ school bonds $(\beta=-.08, p<$. $05)$. Discrimination at $\mathrm{W} 2$ did not have an effect on aggression at $\mathrm{W} 3$ in the multivariate models, but was significantly correlated with aggression at $\mathrm{W} 3$ in the bivariate analysis $(r=$ $0.22, p<.05)$. Discrimination at $\mathrm{W} 3$, however, was positively associated with W5 aggression $(\beta=.09, p<.05)$.

Depressive symptoms at W2 were not associated with W3 aggression, and neither was the path from W3 depressive symptoms to W5 aggression. School bonds at W2 were negatively associated with $\mathrm{W} 3$ aggression $(\beta=-.12, p<.05)$, and $\mathrm{W} 3$ school bonds were negatively associated with W5 aggression $(\beta=-.12, p<.05)$. The path from W2 delinquent peer associations to $\mathrm{W} 3$ aggression showed a marginal positive association $(\beta=.09, p=.07)$, whereas the path from $\mathrm{W} 3$ delinquent peer associations to W5 aggression was positively associated $(\beta=.13, p<.01)$. Several demographic predictors were also associated with aggression. At W3 $(\beta=-.08, p<.05)$ and W5 $(\beta=-.07, p=.08)$, females had lower levels 
of aggression than males, and at W5, those living in remote communities reported lower levels of aggression than those living in non-remote communities $(\beta=-.10, p<.01)$.

Table 4 presents the bootstrapped indirect effects linking discrimination at W2 with aggression at W5 via W3 mediators. The full-longitudinal indirect effects were significant for perceived discrimination $(b=.049,95 \% C I=.006, .093)$, school bonds $(b=.010,95 \%$ $C I=.001, .028)$, and delinquent peer associations $(b=.011,95 \% C I=.001, .029)$. To summarize, the longitudinal indirect effects indicated that, as expected, the mediating mechanisms through which discrimination influences aggression are decreased school bonds and increased delinquent peer associations. Contrary to expectations, depressive symptoms were not associated with aggression and was not a significant mediator linking discrimination to aggression.

\section{Moderation Models}

Moderating effects were added and tested separately for each of the three mechanisms. For the three interaction terms predicting W3 aggression using W2 predictors, no moderating effects were present (results not shown). One of the three interaction terms predicting W5 aggression using W3 predictors was significant (see Table 5 for results). Contrary to expectations, school bonds and delinquent peer associations did not have a moderating effect at either wave. Depressive symptoms at W3 moderated the effect of discrimination at W3 on aggression at W5 $(b=-.01, p<.05)$, although not in the hypothesized direction. We plotted the interaction at $-/+1$ S.D. around the mean for both discrimination and depressive symptoms. As shown in Figure 2, the effect of discrimination on aggression was positive in direction and significant at low levels of depressive symptoms ( and flat and non-significant at high levels of depressive symptoms (simple slope $=0.05 ; p=$ 0.37).

\section{DISCUSSION}

Criminological scholarship has increasingly focused on racial/ethnic discrimination, and its effects on multiple social and individual processes have recently been used to explain racial and ethnic variations in offending (Agnew 2016; Unnever and Gabbidon 2011). Despite this, few criminological studies focus on Indigenous populations or risk factors that are culturally-relevant to this population. North American Indigenous youth develop within a unique cultural and social context shaped by a legacy of historical cultural losses and traumas, and social and economic disadvantage (Whitbeck et al. 2014). These sociohistorical factors make Indigenous individuals and communities likely to experience certain types of risk and unique ways of coping with oppression (Pridemore 2004). A contemporary manifestation of this historical legacy is racial and ethnic discrimination, which is intricately woven into the social fabric in which Indigenous youth develop (Whitbeck et al. 2014) and provides an ongoing context in which communities, families, and individuals operate (Belcourt-Ditloff and Stewart 2000; Evans-Campbell 2008).

We extend this emerging body of work by examining the mediating and moderating mechanisms through which discrimination leads to aggressive delinquency among reservation/reserve residing Indigenous youth in the upper-Midwest of the U.S. and Canada. 
Given the unique geographic, social, cultural, and historic context of many Indigenous communities, this research has the potential to unpack the black box of how strains such as discrimination lead to delinquency, and possibly elucidate the inconsistent findings in the broader GST literature focused on race/ethnicity (e.g., Leeper Piquero and Sealock 2010). Moreover, we add to this body of literature by focusing on experiences of discrimination perpetrated by adult authority figures, which we believe has important relevance for early life course development among Indigenous youth. Discrimination is a multidimensional construct and consequences of racial/ethnic discrimination likely vary according to these different dimensions (Benner and Graham 2013; Brondolo et al. 2005). Understanding the mechanisms through which discrimination is likely to lead to crime requires interrogating whether and how various dimensions of discrimination are differentially associated with criminogenic processes. These findings have general criminological relevance for the study of race and crime and GST, and specific relevance for Indigenous offending and ways in which existing frameworks may be adapted to account for unique Indigenous contexts.

One core argument, based on an integrated version of GST (Agnew 2006), posits that perceptions and experiences of discrimination perpetrated by adult authority figures influence the inner-worlds of adolescents and their early experiences with social institutions. Depressive symptoms, school bonds, and delinquent peer associations were examined as possible mediators and moderators linking discrimination to delinquency. Although discrimination may directly influence aggression when its frequency and intensity are high (e.g., Unnever and Gabbidon 2011), the results show that the most potent explanations linking discrimination to aggression are indirect and/or conditioned by secondary criminogenic factors. The results of the current study revealed partial support for the mediation hypotheses derived from GST with school bonds and delinquent peer associations explaining most of the indirect association between discrimination from adult authority figures and delinquency. The role of negative affect, which is central to GST, had a more complex moderating effect. As such, GST appears to be a useful framework for understanding offending among Indigenous youth, but requires contextualization of each part of the model to be relevant and explain how the theory operates within unique social, cultural, geographic, and historic contexts.

As youth age and their social worlds grow, opportunities to experience discrimination increase in frequency and may have a stronger effect on subsequent delinquency. Early experiences of discrimination at W2 of the study were not directly associated with aggression. They were, however, indirectly associated with later aggression through accumulated experiences of discrimination at W3 of the study (see also Sittner Hartshorn et al. 2012). These findings align with emerging evidence that shows discrimination as an early risk factor for delinquency, and one that likely predicts chronic trajectories of maladaptive behavior throughout the early life course (Evans et al. 2016). This finding also supports a stress proliferation argument, which posits that subsequent stressors emanating from earlier experiences of discrimination link it with delinquent behavior. Although stressors within other domains were not considered, chronic exposure to discrimination across time points may be considered evidence of cumulative and compound risk (De Coster and Thompson 2016). 
Contrary to expectations, discrimination from adult authority figures was only marginally associated with depressive symptoms, and did not mediate the discrimination-delinquency association. This finding contradicts multiple studies among African American youth in which depressive symptoms accounted for a portion of the variation between discrimination and delinquency (Brody et al. 2006; Gibbons et al. 2004; Simons et al. 2003), and prior Indigenous research showing depressive symptoms as a mediator between other strains and suicide ideation (Ivanich and Teasdale 2018; Walls et al. 2007) and heavy alcohol use (Eitle et al. 2013). Three factors may explain this lack of mediation. First, given the outcome is overt aggression, different emotions such as anger may be a better psychosocial mediator linking discrimination to delinquency, which has been supported by previous research among Indigenous youth (Sittner Hartshorn et al. 2011). According to Agnew (2006), anger is a more potent emotion that creates a strong desire to correct perceived injustices and disposes individuals to other-directed crime. Prior tests of GST among Indigenous samples suggests that depressive symptoms appears to be a stronger mediator when the outcome is suicide ideation or substance use, compared to more general externalized forms of delinquency (Eitle and Eitle 2016). Second, prior research suggests that discrimination by adult authority figures is less relevant for psychological adjustment compared to discrimination by peers (Benner and Graham 2013). As such, it is plausible that depressive symptoms may mediate the effect of discrimination on delinquency when alternative contextual sources of discrimination such as peers are examined. Third, the CESD scale (Radloff 1977) may capture trait-based rather than state-based depression (Dumenci and Windle 1996). According to GST, state-based emotions are more consistently found to mediate the strain-delinquency association (Moon et al. 2009).

Depressive symptoms did, however, moderate the effect of discrimination on delinquency, albeit in a theoretically contradictory manner. According to GST, we would expect the positive association between discrimination and aggression to become stronger as depressive symptoms increase, yet the results show that the association weakened as depressive symptoms increased. As previously noted, internalizing symptoms may promote inward rather than outward directed forms of violence (Agnew 2006). Moreover, prior psychometric research on depressive symptom scales among Indigenous people indicate higher endorsement of somatic complaints than is found in other Western populations which have stronger associations with major depressive disorder than negative affect, interpersonal difficulties, or positive affect (Armenta et al. 2014). These findings call into question the utility of Western conceptualizations of depression that may not accurately reflect the Indigenous experience or an adequate cultural response to psychological distress and ongoing exposure to discrimination and historical traumas. Taken together, instead of encapsulating cognitive schemas that increase the likelihood of responding to strain with aggression as previously found (e.g., Manasse and Ganem 2009), depression among Indigenous youth may encapsulate cognitive schemas that make them less likely to respond to strain with aggression. Additional research among diverse samples is necessary for understanding variations in racial and cultural expressions of emotion and manifestations of distress, and how this may influence the core mechanisms of GST and its ability to explain racial disparities in crime. 
In addition to negative affect, Unnever and Gabbidon (2011) argued that discrimination inhibits minority youths' ability to form strong bonds with major social institutions, which undermines a developmentally salient form of social control. The current study indicates that school authority figures are the most common source of discrimination, and not surprisingly, are implicated in decreased school bonding during early adolescence for these Indigenous youth (see also Crawford et al. 2010). A majority of the youth in this sample attend school on-reservation/reserve land $(55.4 \%)$ or, often by necessity, off-reservation land $(31.2 \%)$. Given the rural geography of the sample and the shortage of Indigenous teachers, many nonIndigenous students and staff are present in these schools. Consequently, opportunities to experience discrimination are not limited by location of the school in which participants attend.

Discrimination was associated with increased aggression through this undermining of school bonds, which supports prior research (Brody et al. 2010; Unnever et al. 2016a) and the mediation propositions derived from an integrated GST (Agnew 2006). Although school factors are a strong source of resilience among Indigenous youth (LaFromboise et al. 2006), they do not appear to buffer the deleterious effects of ongoing discrimination by adults. Consequently, these experiences may lead to disengagement from school and ultimately to school dropout (Unnever et al. 2016b). Moreover, a recent study of Indigenous adults indicates that only half had conversations about college while growing up (National Public Radio, Harvard T.H. Chan School of Public Health, and the Robert Wood Johnson Foundation 2017), which may reflect internalized multigenerational effects of discrimination on educational attainment and aspirations. Taken together, an important form of social capital is undermined and may set in motion an amplification process in which damaged social bonds and stressors such as discrimination reciprocally interact with one another to sustain heightened aggressive and analogous behavior (De Coster and Thompson 2016; Slocum 2010) in Indigenous communities.

In addition to school bonds, perceptions and experiences of discrimination, as hypothesized, increased delinquent peer associations, which in turn, increased delinquent behavior. This aligns with previous research among Indigenous (Cheadle and Whitbeck 2011) and African American youth (Gibbons et al. 2004; Simons and Burt 2011; Unnever et al. 2016b). Adolescents may internalize the underlying messages conveyed through interpersonal discrimination from adult authority figures, which combined with decreased social control (as evinced by the direct effect from school bonds to delinquent peer associations) and social and geographic isolation, may lead youth to drift into groups of other disaffected peers. The rural and cultural context of the reservation/reserves shapes the composition of peer networks such that youth are embedded in enduring and dense peer groups (Whitbeck et al. 2014). Consequently, the positive association between discrimination and delinquent peer associations may portend long lasting consequences across the early life course that extend beyond individuals. Contrary to expectations, delinquent peer associations did not moderate the discrimination-delinquency association. Brody and colleagues (2006) found that prosocial peer relationships buffered the effect of discrimination on delinquency among African American youth. Perhaps prosocial peer relationships are conceptually distinct from delinquent peer associations, as opposed to the opposite end of an underlying continuum, 
and act as a better conditional factor, whereas delinquent peer associations may act as a better mediating mechanism.

\section{Limitations and Directions for Future Research}

Several limitations warrant discussion. First, the data come from one Indigenous cultural group and may not be generalizable to all Indigenous youth in the U.S. and Canada. In addition, the data come from rural reservation/reserve communities, and may not be generalizable to youth of the same cultural group residing in urban areas. As argued previously, the socio-historical processes that shape discrimination and the ways in which it is manifested and perceived by others may vary across racial, ethnic, and cultural groups (e.g., Unnever and Gabbidon 2011). As such, research would benefit by taking a withingroup and within-culture approach and using the accumulated evidence to make comparisons and generalizations between groups and Indigenous cultures, thereby expanding our understanding of discrimination and delinquency in general, and among Indigenous youth specifically.

Second, some measurement limitations should be considered when interpreting these results. Although the measure of discrimination was limited to adult authority figures, other contextual factors such as race/ethnicity of the perpetrator (e.g., Rucker et al. 2013), relationship with perpetrator, location of discrimination (e.g., Riina et al. 2013), and propensity to perceive experiences as discriminatory may be important in understanding how perceived discrimination influences delinquency. These limitations, however, are present in all of the prior studies examining the association between discrimination and crime. In addition, our measure does not encompass all aspects of discrimination within this domain and likely misses salient instances of discrimination (e.g., neighbors, parents of peers, employers). Bastos et al. (2010), however, argued that no measurement instrument would be able to fully capture all instances of discrimination. The measure from which the questions were adapted (Schedule of Racist Events; Landrine and Klonoff 1996) was developed to emphasize African American experiences, and was also adapted for use in the FACHS study (e.g., Simons et al. 2003; Burt et al. 2012). Despite extensive input from community members on ways to adapt these items to be relevant for Indigenous youth, this measure may not fully capture Indigenous experiences with discrimination. Future research would benefit by examining these possible methodological effects and their implications for understanding the conditions under which discrimination influences delinquent behavior.

Moreover, the measure of negative affect does not necessarily capture responses to specific strains (state-based emotions), which may influence the mediation and moderation results (Agnew 2006). The measure of peer delinquency was derived from reports from the respondent, potentially introducing measurement error because individuals have a tendency to project their own delinquency onto reports of their friends' delinquency (Boman et al. 2012). Social network measures of peer delinquency may provide better conclusions about the association between discrimination and delinquent peer associations over time.

Third, intervals between observations may be too long to observe mediating/moderating effects or large effect sizes. After controlling for prior levels of each mediator/outcome, there is a smaller amount of variation to be explained by other variables, which may account 
for some of the small effect sizes, especially over the three years studied here. Moreover, given the larger number of statistical tests embedded within the models, type I error inflation may be an issue. Separate sensitivity checks on the mediation and moderation models were conducted using the false discovery rate correction developed by Benjamini and Hochberg (1995), which adjusts p-values for false positive results. Using a false discovery rate ( $q$ value) of 0.05 , moderation tests were unaffected by this adjustment. The indirect effect for delinquent peer associations remained significant; however, school bonds was marginally significant $(p<.10)$ when $p$-values are adjusted at a false discovery rate ( $q$-value) of 0.05 . Despite being driven and supported by theory, some of the findings could be due to chance alone.

\section{CONCLUSION}

Perceptions and experiences of discrimination appear to be a strong generalizable risk factor for delinquency among racial/ethnic minority youth; however, the historical and contemporary manifestations of discrimination and its resulting consequences are likely unique for youth belonging to different racial, ethnic, and cultural groups, and must be understood within this context. Crime in Indigenous communities can be understood as a response to ongoing historical oppression (Poupart 2002), which is perpetuated through discrimination (Burnette and Figley 2017). Likewise, historical cultural losses and traumas magnify the cultural salience and impact of discrimination on individual and collective wellbeing (Evans-Campbell 2008). Consequently, discrimination can be considered a fundamental criminogenic stressor among Indigenous youth and one that portends deleterious consequences for Indigenous adolescent development.

Although GST is a useful lens through which to study discrimination and delinquency, applications of this theory to Indigenous youth are lacking. Given the diversity of Indigenous groups in North America, more within-culture research is necessary to advance our understanding of the mechanisms linking discrimination, as well as other general and unique types of strains, to delinquency in a population that has been left behind by criminological research. This study focuses on core parts of GST to understand why exposure to discrimination leads to delinquency, specifically through delinquent peer associations and damaged school bonds. A crucial next step is to understand why chronic exposure to discrimination does not lead to delinquency. This would allow us to test additional aspects of GST, and identify whether general (e.g., racial/ethnic socialization) and culturally relevant (e.g., involvement in traditional cultural activities) buffers found in the extant literature (e.g., Burt et al. 2012; Whitbeck et al. 2002) operate similarly for Indigenous youth. As Barlow and Walkup (2008) eloquently stated, "the First Americans have much to teach us" (p. 843). Focusing on Indigenous populations and key risk factors such as discrimination may provide fruitful avenues for elaborating, contextualizing, and/or generating new theories relevant to the broader discipline and disentangling the complex link between offending and socially constructed distinctions such as race/ethnicity.

\section{Acknowledgements:}

The authors would like to acknowledge community-based Advisory Boards, Lisa Kort-Butler, Kirk Dombrowski, Dan Hoyt, Jonathan Brauer, Les Whitbeck, and Melissa Walls for their review of earlier drafts of this manuscript. 
Funding Source:

This study is based on a chapter from the first author's doctoral dissertation work, which was supported by a J.J. and Elenor S. Ogle Fellowship at the University of Nebraska. This research was also supported by the National Institute on Drug Abuse under grants R01DA13580 and T32DA037183, the National Institute of Mental Health under grant R01MH67281, and the National Institute on Alcohol Abuse and Alcoholism under grant R01AA020299. The content is solely the responsibility of the authors and does not necessarily represent the official views of the National Institutes of Health.

\section{References}

Agnew Robert. 1992 "Foundation for a General Strain Theory of Crime and Delinquency." Criminology 30: 47-88.

Agnew Robert. 2001 "Building on the Foundation of General Strain Theory: Specifying the Types of Strain Most Likely to Lead to Crime and Delinquency." Journal of Research in Crime and Delinquency 38: 319-361.

Agnew Robert. 2006 Pressured Into Crime: An Overview of General Strain Theory Los Angeles, CA: Roxbury.

Alegria Margarita, Takeuchi David, Canino Glorisa, Duan Naihua, Shrout Patrick, Meng Xiao-Li, Vega Williams, Zane Nolan, Vila Doryliz, Woo Meghan, Vera Mildred, Guarnaccia Peter, AguilarGaxiola Sergio, Sue Stanley, Escobar Javier, Lin Keh-Ming, and Gong Fong. 2004 "Considering Context, Place and Culture: The National Latino and Asian American Study.” International Journal of Methods in Psychiatric Research 13: 208-220. [PubMed: 15719529]

Armenta Brian, Hartshorn Kelley Sittner, Whitbeck Les, Crawford Devan, and Hoyt Dan. 2014 “A Longitudinal Examination of the Measurement Properties and Predictive Utility of the Center for Epidemiological Studies Depression Scale among North American Indigenous Adolescents." Psychological Assessment 26: 1347-1355. [PubMed: 25181394]

Baek Hyunin, Roberts Amanda M., and Higgins George E.. 2018 "The Impact of Family Indifference on Delinquency Among American Indian Youth: A Test of General Strain Theory.” Journal of Ethnicity in Criminal Justice 16: 57-75.

Barlow Allison, and Walkup John. 2008 "The First Americans Have Much to Teach Us." Journal of the American Academy of Child \& Adolescent Psychiatry 47: 843-844. [PubMed: 18645415]

Bastos Joao, Celeste Roger, Faerstein Eduardo, and Barros Aluisio. 2010 "Racial Discrimination and Health: A Systematic Review of Scales with a Focus on their Psychometric Properties.” Social Science \& Medicine 70: 1091-1099. [PubMed: 20122772]

Beals Janette, Manson Spero, Mitchell Christina, Spicer Paul, \& AI-SUPERPFP Team. 2003 "Cultural Specificity and Comparison in Psychiatric Epidemiology: Walking the Tightrope in American Indian Research.” Culture, Medicine and Psychiatry 27: 259-289.

Benjamini Yoav, and Hochberg Yosef. 1995 "Controlling the False Discovery Rate: A Practical and Powerful Approach to Multiple Testing." Journal of the Royal Statistical Society (Series B) 57: 289-300.

Belcourt-Dittloff Annjeanette, and Stewart Jera. 2000 "Historical Racism: Implications for Native Americans." American Psychologist 55: 1166-1167. [PubMed: 11080850]

Benner Aprile, and Graham Sandra. 2013 "The Antecedents and Consequences of Racial/Ethnic Discrimination During Adolescence: Does the Source of Discrimination Matter?" Developmental Psychology 49: 1602-1613. [PubMed: 23106845]

Benner Aprile, Wang Yijie, Shen Yishan, Boyle Alaina, Polk Richelle, and Cheng Yen-Pi. 2018 "Racial/Ethnic Discrimination and Well-Being During Adolescence: A Meta-Analytic Review." American Psychologist 73: 855-883. [PubMed: 30024216]

Berkowitz Leonard. 1989 "Frustration-Aggression Hypothesis: Examining and Reformulation." Psychological Bulletin 106: 59-73. [PubMed: 2667009]

Beyers Jennifer, and Loeber Rolf. 2003 “Untangling Developmental Relations between Depressed Mood and Delinquency in Male Adolescents.” Journal of Abnormal Child Psychology 31: 247266. [PubMed: 12774859] 
Bogart Laura, Elliot Marc, Kanouse David, Klein David, Davies Susan, Cuccaro Paula, Banspach Stephen, Peskin Melissa, and Schuster Mark. 2013 “Association Between Perceived Discrimination and Racial/Ethnic Disparities in Problem Behaviors among Preadolescent Youths.” American Journal of Public Health 103: 1074-1081. [PubMed: 23597387]

Boman John, Ward Jeffrey, Gibson Chris, and Leite Walter. 2012 "Can a Perceptual Peer Deviance Measure Accurately Measure a Peer's Self-Reported Deviance?” Journal of Criminal Justice 40: 463-471.

Brody Gene, Chen Yi-Fu, Murry Velma McBride, Ge Xiaojia, Simons Ronald, Gibbons Frederick, Gerrard Meg, and Cutrona Carolyn. 2006 "Perceived Discrimination and the Adjustment of African American Youths: A Five-Year Longitudinal Analysis with Contextual Moderation Effects." Child Development 77: 1170-1189. [PubMed: 16999791]

Brody Gene, Kogan Steven, and Chen Yi-Fu. 2012 "Perceived Discrimination and Longitudinal Increases in Adolescent Substance Use: Gender Differences and Mediational Pathways." American Journal of Public Health 102: 1006-1011. [PubMed: 22420807]

Brondolo Elizabeth, Kelly Kim, Coakley Vonetta, Gordon Tamar, Thompson Shola, Levy Erika, Cassells Andrea, Tobin Jonathan, Sweeny Monica, and Contrada Richard. 2005 "The Perceived Ethnic Discrimination Questionnaire: Development and Preliminary Validation of a Community Version.” Journal of Applied Social Psychology 35: 335-365.

Brown Christina, and Bigler Rebecca. 2005 “Children's Perceptions of Discrimination: A Developmental Model.” Child Development 76: 533-553. [PubMed: 15892777]

Burnette Catherine, and Figley Charles. 2017 "Historical Oppression, Resilience, and Transcendence: Can a Holistic Framework Help Explain Violence Experienced by Indigenous People?" Social Work 62: 37-44. [PubMed: 28395035]

Burt Callie Harbin, Lei Man Kit, and Simons Ronald L.. 2017 "Racial Discrimination, Racial Socialization, and Crime Over Time: A Social Schematic Theory Model.” Criminology 55: 938979.

Burt Callie Harbin and Simons Ronald L.. 2015 "Interpersonal Racial Discrimination, Ethnic-Racial Socialization, and Offending: Risk and Resilience among African American Females.” Justice Quarterly 32: 532-570.

Burt Callie, Simons Ronald L., and Gibbons Frederick X.. 2012 "Racial Discrimination, Ethnic-Racial Socialization, and Crime: A Micro-sociological Model of Risk and Resilience." American Sociological Review 77: 648-677. [PubMed: 24058204]

Cheadle Jacob, and Whitbeck Les. 2011 "Alcohol Use Trajectories and Problem Drinking Over the Course of Adolescence: A Study of North American Indigenous Adolescents and Their Caretakers." Journal of Health and Social Behavior: 52 228-245. [PubMed: 21558489]

Cole David, and Maxwell Scott. 2003 “Testing Mediation Models With Longitudinal Data: Questions and Tips in the Use of Structural Equation Modeling." Journal of Abnormal Psychology 112: 558577. [PubMed: 14674869]

Crawford Devan, Cheadle Jacob, and Whitbeck Les. 2010 "Tribal vs. Public Schools: Perceived Discrimination and School Adjustment among Indigenous Children from Early to MidAdolescence." Journal of American Indian Education 49: 80-100.

DeCoster Stacy and Kort-Butler Lisa. 2006 "How General is General Strain Theory? Assessing Determinacy and Indeterminacy Across Life Domains." Journal of Research in Crime and Delinquency 43: 297-325.

DeCoster Stacy, and Thompson Maxine. 2017 "Race and General Strain Theory: Microaggressions as Mundane Environmental Stresses.” Justice Quarterly 34: 903-930.

Dodge Kenneth, and Pettit Gregory. 2003 "A Biosocial Model of the Development of Chronic Conduct Problems in Adolescence.” Developmental Psychology 39: 349-371. [PubMed: 12661890]

Dumenci Levent, and Windle Michael. 1996 “A Latent Trait-State Model of Adolescent Depression Using the Center for Epidemiologic Studies-Depression Scale.” Multivariate Behavioral Research 31: 313-330. [PubMed: 26741070]

Duran Eduardo, and Duran Bonnie. 1995 Native American Postcolonial Psychology Albany, NY: State University of New York Press. 
Eitle David, and Eitle Tamela McNulty. 2016 "General Strain Theory and Delinquency: Extending a Popular Explanation to American Indian Youth.” Youth \& Society 48: 470-495. [PubMed: 27217594]

Eitle Tamela McNulty, Eitle David, and Johnson-Jennings Michelle. 2013 "General Strain Theory and Substance Use Among American Indian Adolescents.” Race and Justice 3: 3-30. [PubMed: 23826511]

Enders Craig, Baraldi Amanda, and Cham Heining. 2014 "Estimating Interaction Effects with Incomplete Predictor Variables.” Psychological Methods 19: 39-55. [PubMed: 24707955]

Evans Sara, Simons Leslie Gordon, and Simons Ronald. 2016 "Factors that Influence Trajectories of Delinquency Throughout Adolescence.” Journal of Youth and Adolescence 45: 156-171. [PubMed: 25292150]

Evans-Campbell Teresa. 2008 "Historical Trauma in American Indian/Native Alaska Communities: A Multilevel Framework for Exploring Impacts on Individuals, Families, and Communities.” Journal of Interpersonal Violence 23: 316-338. [PubMed: 18245571]

Fryberg Stephanie, Markus Hazel, Oyserman Daphna, and Stone Joseph. 2008 "Of Warrior Chiefs and Indian Princesses: The Psychological Consequence of American Indian Mascots.” Basic and Applied Social Psychology 30: 208-218.

Gibbons Frederick, Gerrard Meg, Cleveland Michael, Wills Thomas, and Brody Gene. 2004 "Perceived Discrimination and Substance Use in African American Parents and Their Children: A Panel Study." Journal of Personality and Social Psychology 86: 517-529. [PubMed: 15053703]

Harris Kathleen Mullan, Duncan Greg, and Boisjoly Johanne. 2002 "Evaluating the Role of "Nothing to Lose” Attitudes on Risky Behavior in Adolescence." Social Forces 80: 1005-1039.

Hautala Dane, Sittner Kelley, and Whitbeck Les. 2016 "Prospective Childhood Risk Factors for Gang Involvement among North American Indigenous Adolescents." Youth Violence and Juvenile Justice 14: 390-410. [PubMed: 28018134]

Hoskin Anthony. 2013 "Experiencing Prejudice and Violence among Latinos: A General Strain Theory Approach.” Western Criminology Review 14: 25-38.

Hu Li-Tze, and Bentler Peter. 1999 "Cutoff Criteria for Fit Indices in Covariance Structure Analysis: Conventional Criteria versus New Alternatives.” Structural Equation Modeling: A Multidisciplinary Journal 6: 1-55.

Ivanich Jerreed, and Teasdale Brent. 2018 "Suicide Ideation among Adolescent American Indians: An Application of General Strain Theory." Deviant Behavior 39: 702-715.

Jang Sung Joon, and Rhodes Jeremy. 2012 "General Strain and Non-Strain Theories: A Study of Crime in Emerging Adulthood.” Journal of Criminal Justice 40: 176-186.

Kaufman Joanne, Rebellon Cesar, Thaxton Sherod, and Agnew Robert. 2008 “A General Strain Theory of Racial Difference in Criminal Offending." Australian \& New Zealand Journal of Criminology 41: 421-437.

Kofler Michael, McCart Michael, Zajac Krisyn, Ruggerio Kenneth, Saunders Benjamin, and Kilpatrick Dean. 2011 "Depression and Delinquency Covariation in an Accelerated Longitudinal Sample of Adolescents." Journal of Consulting and Clinical Psychology 79: 458-469. [PubMed: 21787049]

LaFromboise Teresa, Hoyt Dan, Oliver Lisa, and Whitbeck Les. 2006 "Family, Community, and School Influences on Resilience among American Indian Adolescents in the Upper Midwest." Journal of Community Psychology 34: 193-209.

Landrine Hope, and Klonoff Elizabeth. 1996 "The Schedule of Racist Events: A Measure of Racial Discrimination and a Study of its Negative Physical and Mental Health Consequences." Journal of Black Psychology 22: 144-168.

Nicole Leeper Piquero, and Sealock Miriam. 2010 "Race, Crime, and General Strain Theory." Youth Violence and Juvenile Justice 8: 170-186.

Mackinnon David, Lockwood Chondra, and Williams Jason. 2004 "Confidence Limits for the Indirect Effect: Distribution of the Product and Resampling Methods." Multivariate Behavioral Research 39: 99-128. [PubMed: 20157642]

Manasse Michelle, and Ganem Natasha. 2009 "Victimization as a Cause of Delinquency: The Role of Depression and Gender.” Journal of Criminal Justice 37: 371-378. 
Martin Favian Alejandro. 2014 "The Coverage of American Indians and Alaska Natives in Criminal Justice and Criminology Introductory Textbooks." Critical Criminology 22: 237-256.

Maxwell Scott, Cole David, and Mitchell Melissa. 2011 "Bias in Cross-Sectional Analyses of Longitudinal Mediation: Partial and Complete Mediation Under and Autoregressive Model.” Multivariate Behavioral Research 46: 816-841. [PubMed: 26736047]

Mazerolle Paul, Burton Velmer, Cullen Francis, Evans T. David, and Payne Gary. 2000 "Strain, Anger, and Delinquent Adaptations Specifying General Strain Theory.” Journal of Criminal Justice 28: 89-101.

Mazerolle Paul, and Maahs Jeff. 2000 "General Strain and Delinquency: An Alternative Examination of Conditioning Influences.” Justice Quarterly 17: 753-778.

McNulty Thomas, and Bellair Paul. 2003 "Explaining Racial and Ethnic Differences in Serious Adolescent Violent Behavior." Criminology 41: 709-748.

Mmari Kristin, Blum Robert, and Nicolette Teufel-Shone. 2010 "What Increases Risk and Protection for Delinquent Behaviors among American Indian Youth?: Findings from Three Tribal Communities." Youth \& Society 41: 382-413.

Moon Byongook, Morash Merry, McCluskey Cynthia Perez, and Hwang Hye-Won. 2009 “A Comprehensive Test of General Strain Theory: Key Strains, Situational- and Trait-Based Negative Emotions, Conditional Factors, and Delinquency.” Journal of Research in Crime and Delinquency 46: $182-212$.

Muthen Linda, and Muthen Begnt. 1998-2010 Mplus User's Guide Sixth Edition Los Angeles, CA: Muthen \& Muthen.

National Public Radio, Harvard T.H. Chan School of Public Health, and the Robert Wood Johnson Foundation. 2017 "Discrimination in America: Experiences and Views of Native Americans" Retrieved February 21, 2018 (https://www.npr.org/documents/2017/nov/NPR-discriminationnative-americans-final.pdf).

Nyborg Vanessa, and Curry John. 2003 "The Impact of Perceived Racism: Psychological Symptoms among African American Boys.” Journal of Clinical Child \& Adolescent Psychology 32: 258-266. [PubMed: 12679284]

Pascoe Elizabeth, and Richman Laura. 2009 "Perceived Discrimination and Health: A Meta-Analytic Review.” Psychological Bulletin 135: 531-554. [PubMed: 19586161]

Pearlin Leonard. 1989 “The Sociological Study of Stress.” Journal of Health and Social Behavior 30: 241-256. [PubMed: 2674272]

Piquero Alex, Paternoster Raymond, Pogarsky Greg, and Loughran Thomas. 2011 "Elaborating the Individual Difference Component in Deterrence Theory." Annual Review of Law and Social Science 7: 335-360

Poupart Lisa. 2002 “Crime and Justice in American Indian Communities.” Social Justice 29: 144-159.

Pridemore Alex. 2004 "Review of the Literature on Risk and Protective Factors of Offending among Native Americans." Journal of Ethnicity in Criminal Justice 2: 45-63.

Priest Naomi, Paradies Yin, Trenerry Brigid, Truong Mandy, Karlsen Saffron, and Kelly Yvonne. 2013 "A Systematic Review of Studies Examining the Relationship between Reported Racism and Health and Wellbeing for Children and Young People.” Social Science \& Medicine 95: 115-127. [PubMed: 23312306]

Radloff Lenore. 1977 “The CES-D Scale: A Self-Report Depression Scale for Research in the General Population.” Applied Psychological Measurement 1: 385-401.

Riina Elizabeth, Martin Anne, Gardner Margo, and Brooks-Gunn Jeanne. 2013 “Context Matters: Links between Neighborhood Discrimination, Neighborhood Cohesion and African American Adolescents' Adjustment.” Journal of Youth and Adolescence 42: 136-146. [PubMed: 22890902]

Robertson Dwanna. 2015 "Invisibility in the Color-Blind Era: Examining Legitimized Racism Against Indigenous People.” American Indian Quarterly 39: 113-153.

Rucker Julian, Neblett Enrique, and Anyiwo Nkemka. 2013 "Racial Identity, Perpetrator Race, Racial Composition of Primary Community, and Mood Responses to Discrimination.” Journal of Black Psychology 40: 539-562.

Schaefer David, Kornienko Olga, and Fox Andrew. 2011 "Misery Does Not Love Company: Network Selection Mechanisms and Depression Homophily.” American Sociological Review 76: 764-785. 
Shaffer David, Fisher Prudence, Lucas Christopher, Dulcan Mina, and Schwab-Stone Mary. 2000 "NIMH Diagnostic Interview Schedule for Children Version IV (NIMH DISC-IV): Description, Differences From Previous Versions, and Reliability of Some Common Diagnoses.” Journal of the American Academy of Child and Adolescent Psychiatry 39: 28-38. [PubMed: 10638065]

Shrout Patrick, and Bolger Niall. 2002 "Mediation in Experimental and Nonexperimental Studies: New Procedures and Recommendations." Psychological Methods 7: 422-445. [PubMed: 12530702]

Simons Ronald, and Burt Callie. 2011 "Learning to be Bad: Adverse Social Conditions, Social Schemas, and Crime.” Criminology 49: 553-598. [PubMed: 21760641]

Simons Ronald, Chen Yi-Fu, Stewart Eric, and Brody Gene. 2003 "Incidents of Discrimination and Risk for Delinquency: A Longitudinal Test of Strain Theory with an African American sample." Justice Quarterly 20: 827-854.

Hartshorn Sittner, Kelley Les Whitbeck, and Hoyt Dan. 2012 "Exploring the Relationships of Perceived Discrimination, Anger, and Aggression among North American Indigenous Adolescents." Society and Mental Health 2: 53-67. [PubMed: 22905334]

Sittner Kelley, and Hautala Dane. 2016 "Aggressive Delinquency among North American Indigenous Adolescents: Trajectories and Predictors.” Aggressive Behavior 42: 274-286. [PubMed: 26350331]

Slocum Lee Ann. 2010 "General Strain Theory and Continuity in Offending Over Time: Assessing and Extending GST Explanations of Persistence.” Journal of Contemporary Criminal Justice 26: 204223.

Sterrett Emma, Jones Deborah, McKee Laura, and Kincaid Carlye. 2011 "Supportive Non-Parental Adults and Adolescent Psychosocial Functioning: Using Social Support as a Theoretical Framework." American Journal of Community Psychology 48: 284-295. [PubMed: 21384233]

Thoits Peggy. 1991 “On Merging Identity Theory and Stress Research.” Social Psychology Quarterly 54: 101-112.

Unnever James, Cullen Francis, and Barnes JC. 2016a "Racial Discrimination, Weakened Social Bonds, and Problematic Behaviors: Testing a Theory of African American Offending." Journal of Research in Crime and Delinquency 53: 139-164.

Unnever James, Cullen Francis, and Barnes JC. 2016b "Racial Discrimination and Pathways to Delinquency: Testing a Theory of African American Offending." Race and Justice

Unnever James, Cullen Francis, Mathers Scott, McClure Timothy, and Allison Marisa. 2009 "Racial Discrimination and Hirschi's Criminological Classic: A Chapter in the Sociology of Knowledge." Justice Quarterly 26: 377-409.

Unnever James, and Gabbidon Shaun. 2011 A Theory of African American Offending: Race, Racism, and Crime New York, NY: Routledge.

Walls Melissa, Chapple Constance, and Johnson Kurt. 2007 "Strain, Emotion, and Suicide Among American Indian Youth.” Deviant Behavior 28: 219-246.

Walters Karina and Simoni Jane. 2002 "Reconceptualizing Native Women's Health: An 'Indigenist' Stress-Coping Model.” American Journal of Public Health 92: 520-524. [PubMed: 11919043]

Warr Mark. 2002 Companions in Crime New York, NY: Cambridge University Press.

Whitbeck Les, Hoyt Dan, McMorris Barbara, Chen Xiaojin, and Stubben Jerry. 2001 "Perceived Discrimination and Early Substance Abuse among American Indian Children." Journal of Health and Social Behavior 42: 405-424. [PubMed: 11831140]

Whitbeck Les, Hartshorn Kelley Sittner, and Walls Melissa. 2014 Indigenous Adolescent Development: Psychological, Social and Historical Contexts New York, NY: Routledge.

Yuan Ke-Hai and Bentler Peter. 2000 "Three Likelihood-Based Methods for Mean and Covariance Structure Analysis with Nonnormal Missing Data.” Sociological Methodology 30: 165-200. 


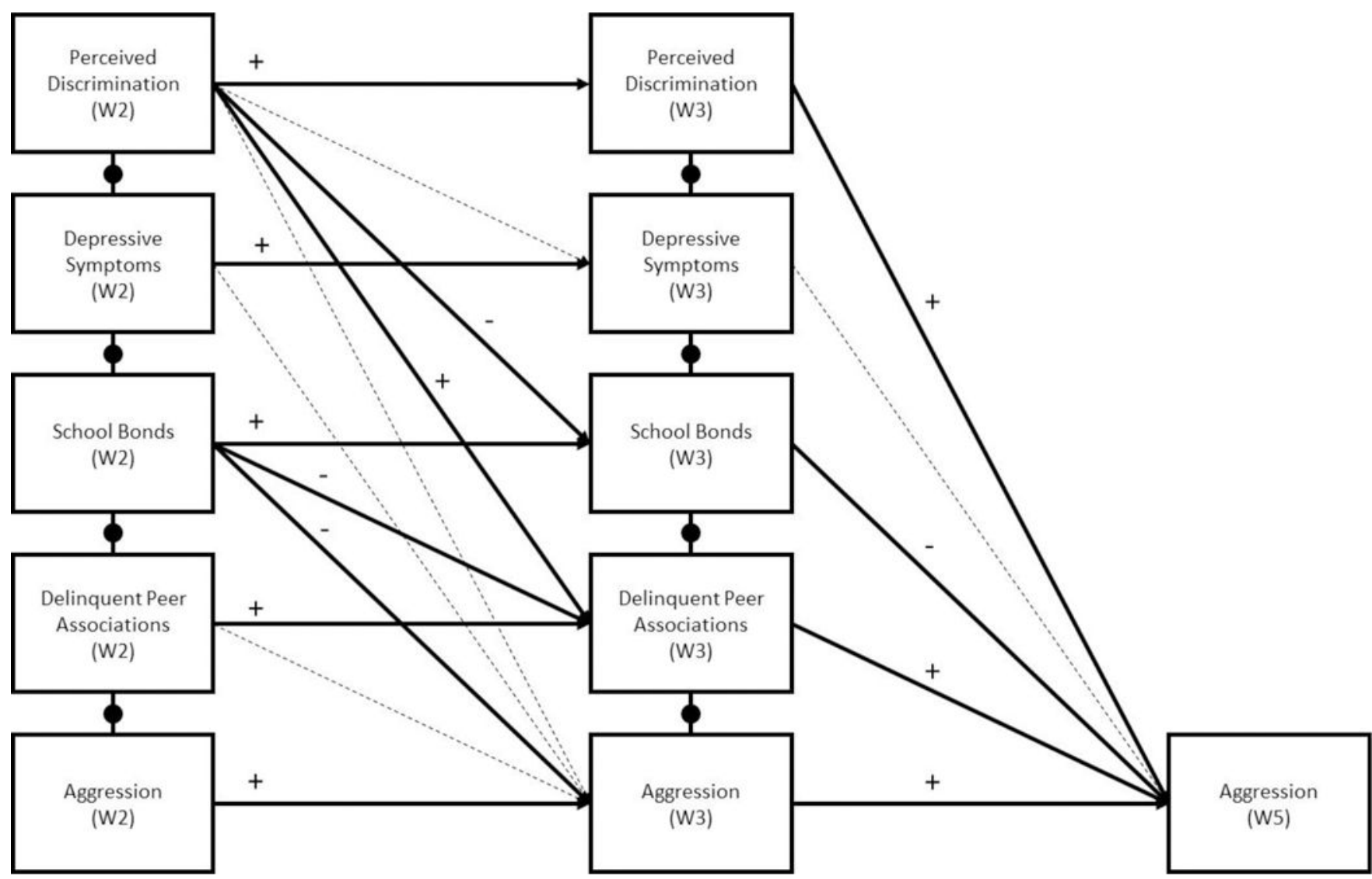

Figure 1.

Summary of final cross-lagged path analysis model linking perceived racial discrimination to aggression (see also Table 3$)$. Solid arrows are statistically significant $(\mathrm{p}<.05)$ and dashed arrows are non-significant. + Positive association; - negative association; $\bullet$ within wave variables were allowed to covary. 


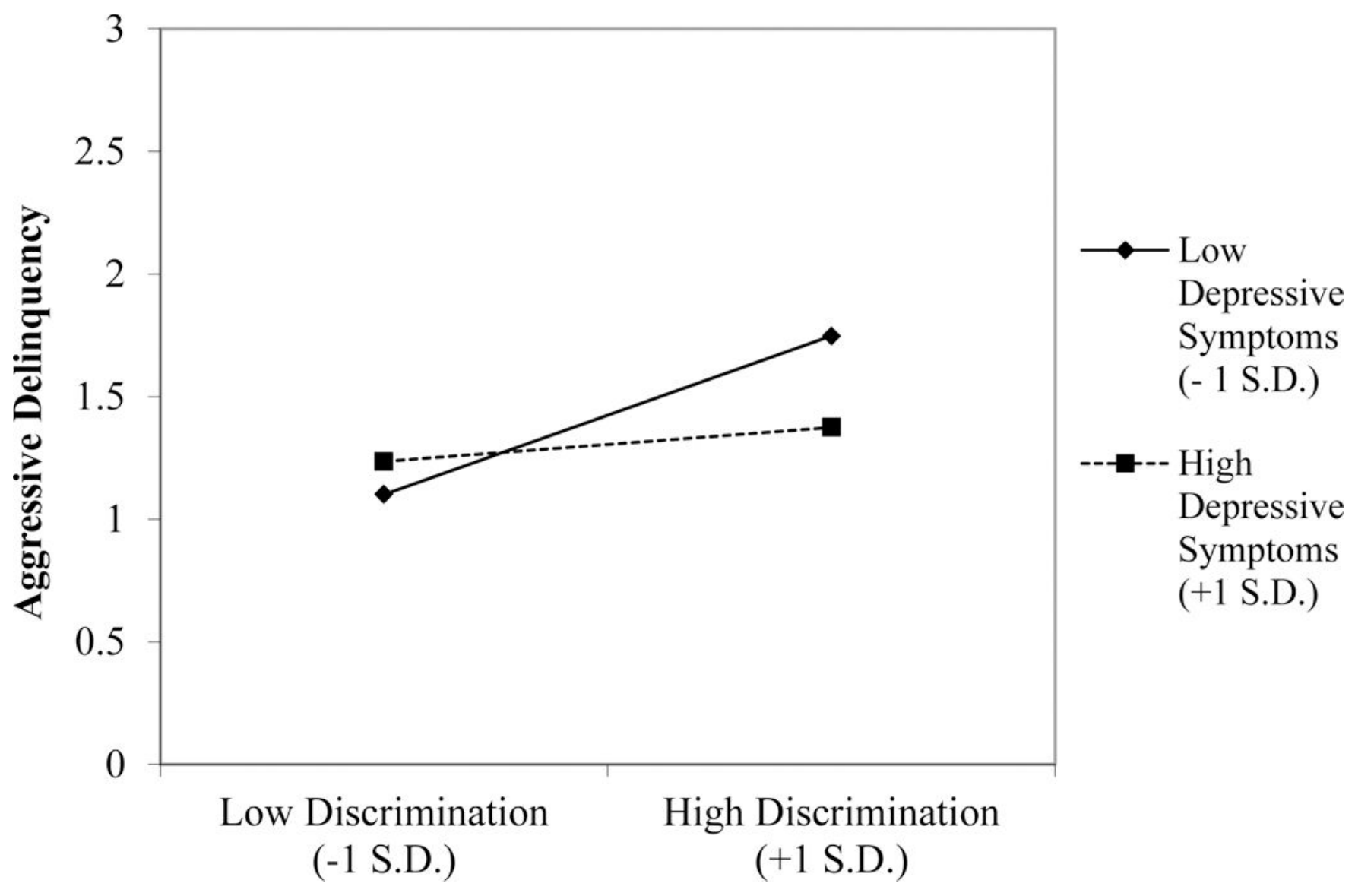

Figure 2.

Moderation plot of the association between discrimination (x-axis) and aggressive delinquency (y-axis) at low (- 1 S.D. below the mean; solid line) and high (+1 S.D. above the mean; dashed line) levels of depressive symptoms. 


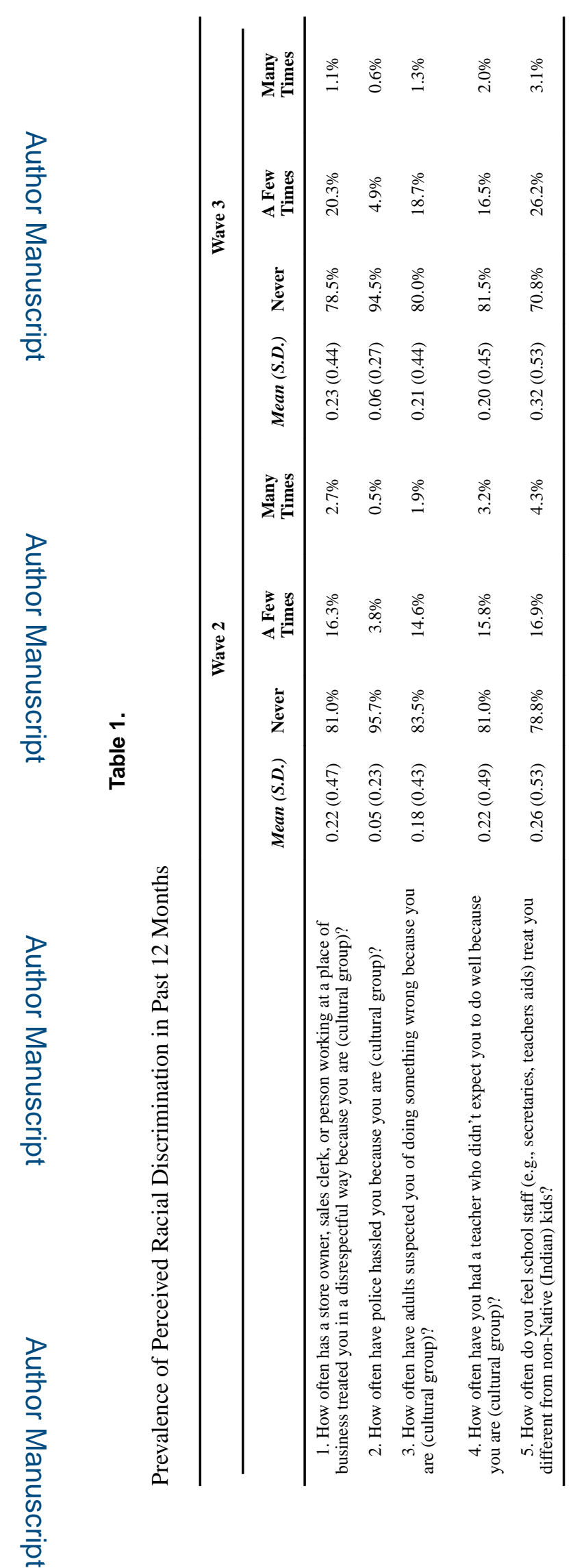

J Res Crime Delinq. Author manuscript; available in PMC 2020 August 01. 


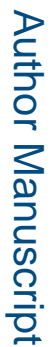

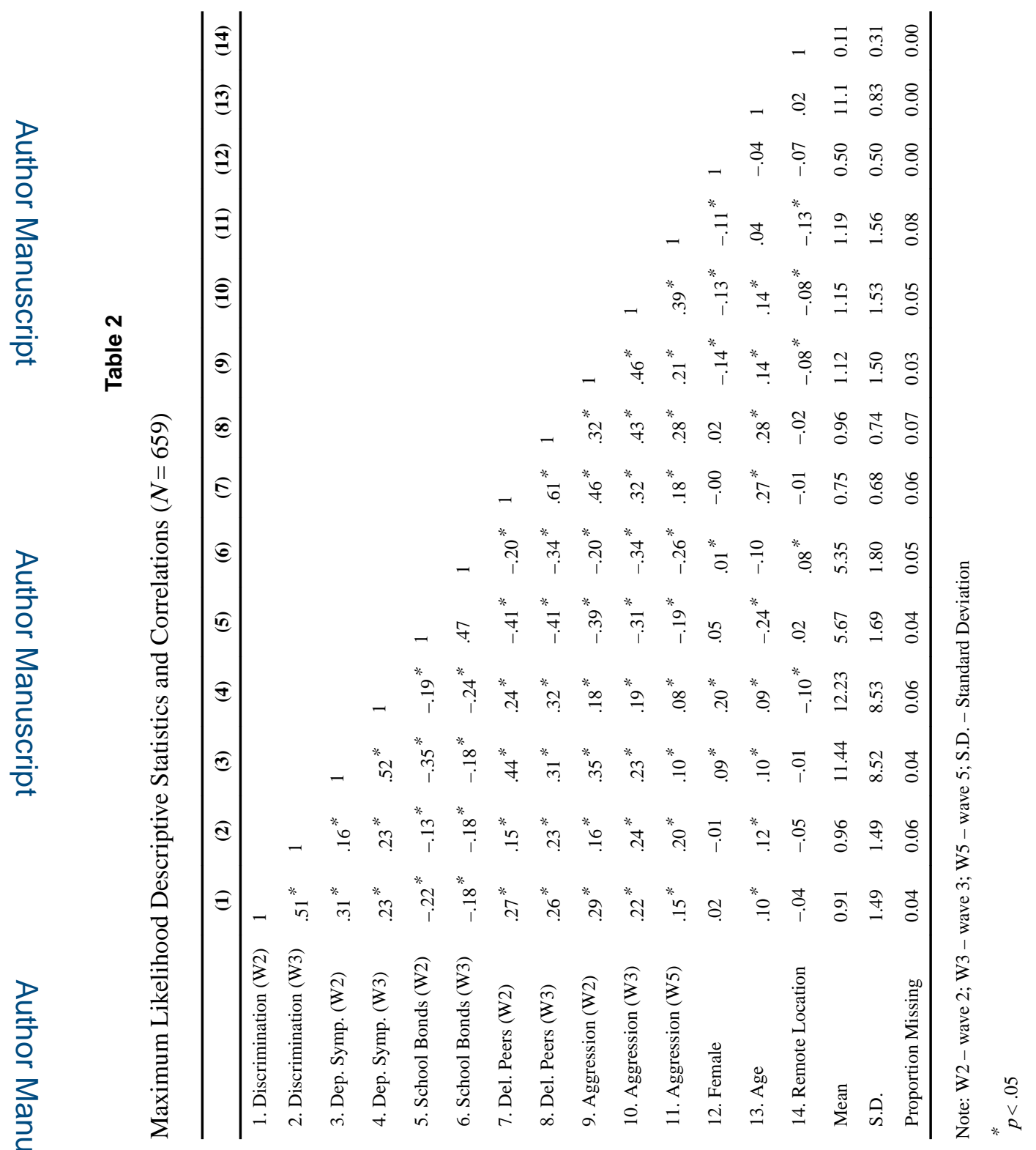




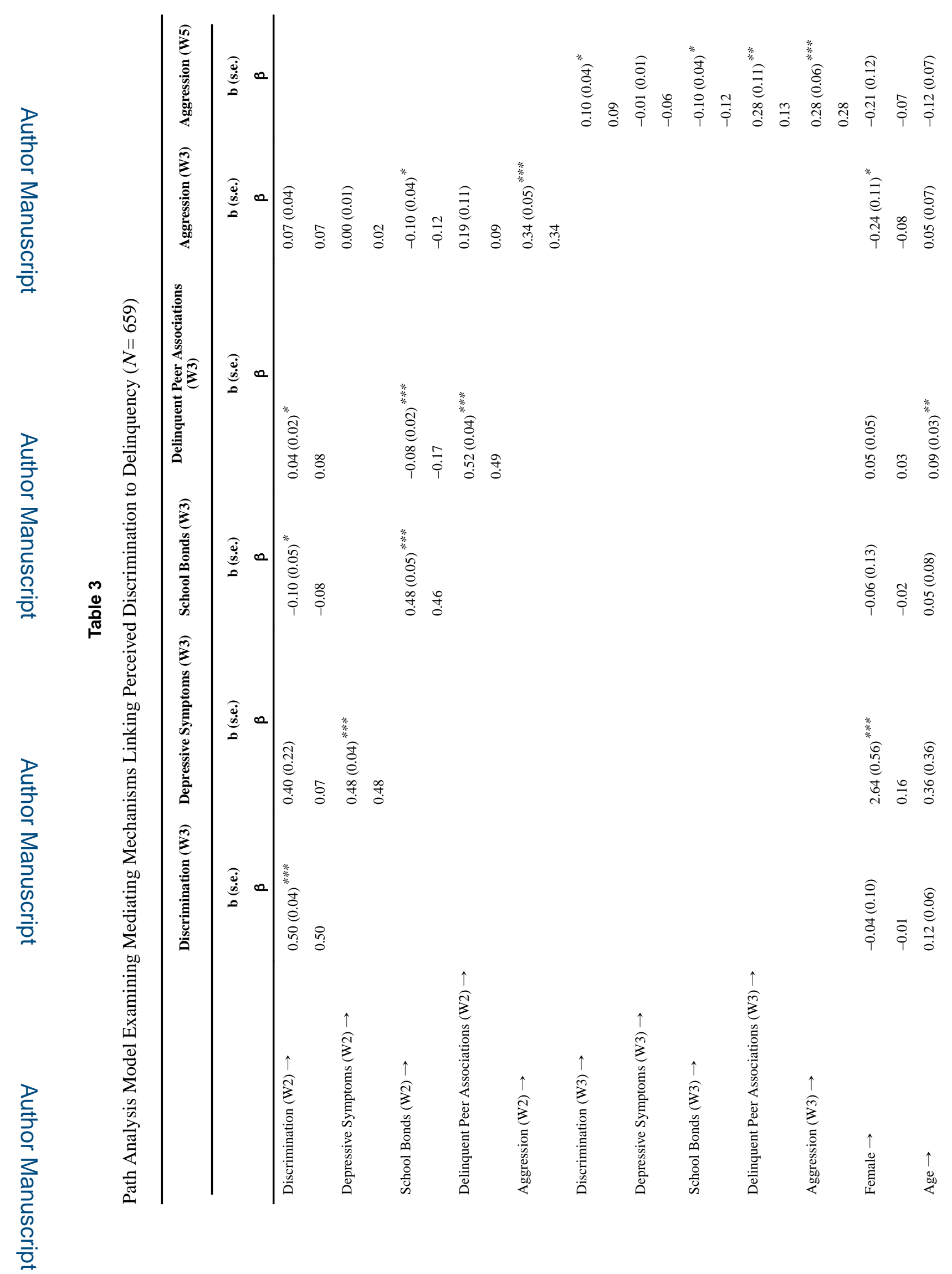

J Res Crime Delinq. Author manuscript; available in PMC 2020 August 01. 


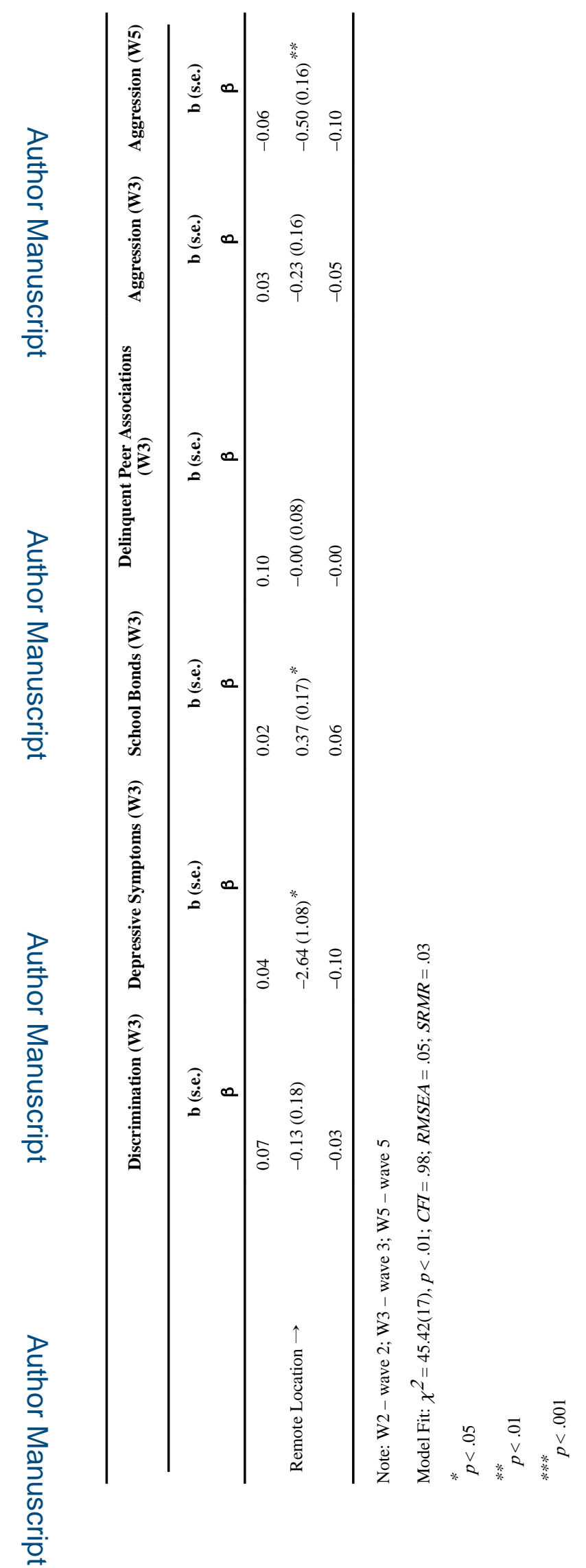

J Res Crime Delinq. Author manuscript; available in PMC 2020 August 01. 
Table 4

Total and Indirect Effects from Wave 2 Discrimination to Wave 5 Aggression $(N=659)$

\begin{tabular}{lcc}
\hline & Estimate & 95\% Confidence Interval \\
\hline Total Effect: & $.085^{*}$ & {$[.035, .137]$} \\
Indirect Effect Via: & & \\
Discrimination (W3) & $.049^{*}$ & {$[.006, .093]$} \\
Depressive Symptoms (W3) & -.004 & {$[-.018, .001]$} \\
School Bonds (W3) & $.010^{*}$ & {$[.001, .028]$} \\
Delinquent Peer Associations (W3) & $.011^{*}$ & {$[.001, .029]$} \\
\hline
\end{tabular}

Note: W3 - wave 3

* $p<.05$ 
Table 5

Maximum Likelihood Regression Models Predicting Wave 5 Aggression with Wave 3 Moderators $(\mathrm{N}=659)$

\begin{tabular}{|c|c|c|c|}
\hline & Model 1 & Model 2 & Model 3 \\
\hline & $\begin{array}{c}\text { b (s.e.) } \\
\beta\end{array}$ & $\begin{array}{c}\text { b (s.e.) } \\
\beta\end{array}$ & $\begin{array}{c}\text { b (s.e.) } \\
\beta\end{array}$ \\
\hline \multirow[t]{2}{*}{ Discrimination } & $0.13(0.05)^{* * *}$ & $0.12(0.04)^{* *}$ & $0.08(0.04)$ \\
\hline & 0.13 & 0.12 & 0.08 \\
\hline \multirow[t]{2}{*}{ Depressive Symptoms } & $-0.01(0.01)$ & $-0.01(0.01)$ & $-0.01(0.01)$ \\
\hline & -0.04 & -0.05 & -0.05 \\
\hline \multirow[t]{2}{*}{ School Bonds } & $-0.10(0.04)^{*}$ & $-0.11(0.04)^{*}$ & $-0.10(0.04)^{*}$ \\
\hline & -0.11 & -0.12 & -0.12 \\
\hline \multirow[t]{2}{*}{ Delinquent Peer Associations } & $0.26(0.11)^{*}$ & $0.26(0.11)^{*}$ & $0.27(0.11)^{*}$ \\
\hline & 0.12 & 0.12 & 0.13 \\
\hline \multirow[t]{2}{*}{ Aggression (W3) } & $0.29(0.06)^{* * *}$ & $0.29(0.06)^{* * *}$ & $0.29(0.06)^{* * *}$ \\
\hline & 0.28 & 0.28 & 0.28 \\
\hline \multirow[t]{2}{*}{ Female } & $-0.20(0.12)$ & $-0.21(0.12)$ & $-0.21(0.12)$ \\
\hline & -0.06 & -0.07 & -0.07 \\
\hline \multirow[t]{2}{*}{ Age } & $-0.12(0.07)$ & $-0.12(0.07)$ & $-0.12(0.07)$ \\
\hline & -0.06 & -0.07 & -0.06 \\
\hline \multirow[t]{2}{*}{ Remote Location } & $-0.46(0.16)^{* *}$ & $-0.53(0.16)^{* *}$ & $-0.50(0.16)^{* *}$ \\
\hline & -0.09 & -0.10 & -0.10 \\
\hline \multirow[t]{2}{*}{ Discrimination $\times$ Depressive Symptoms } & $-0.01(0.01)^{*}$ & & \\
\hline & -0.10 & & \\
\hline \multirow[t]{2}{*}{ Discrimination $\times$ School Bonds } & & $0.04(0.02)$ & \\
\hline & & 0.08 & \\
\hline Discrimination $\times$ Delinquent Peers & & & $0.07(0.07)$ \\
\hline \multirow[t]{2}{*}{ Intercept } & $1.37(0.09)^{* * *}$ & $1.37(0.09)^{* * *}$ & $1.33(0.09)^{* * *}$ \\
\hline & 0.87 & 0.87 & 0.85 \\
\hline
\end{tabular}

Note: All continuous variables centered at their estimated maximum likelihood mean; W3 - Wave 3

* $p<.05$

*** $p<.01$

**** $p<.001$ 